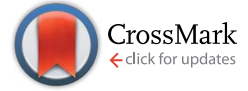

Cite this: RSC Adv., 2016, 6, 39511

Received 15th February 2016 Accepted 11th April 2016

DOI: 10.1039/c6ra04071c

www.rsc.org/advances

\section{The effect of growing time and Mn concentration on the defect structure of ZnO nanocrystals: X-ray diffraction, infrared and EPR spectroscopy $\dagger$}

\author{
Saadet Yildirimcan, ${ }^{\text {ab }}$ Kasim Ocakoglu, ${ }^{\text {*ac }}$ Selma Erat, ${ }^{\text {}}$ Fatih M. Emen, ${ }^{d}$ Sergej Repp ${ }^{e}$ \\ and Emre Erdem*e
}

$\mathrm{ZnO}$ nanopowder was synthesized via a hydrothermal route and characterized with several methods such as XRD, TG/DTA, FT-IR, FE-SEM, TEM and Electron Paramagnetic Resonance spectroscopy (EPR) in order to investigate the effect of growing time and $\mathrm{Mn}$ doping on the defects which occurred. The pure $\mathrm{ZnO}$ nanopowder was obtained in a hexagonal phase with (101) as the preferred orientation except for the one prepared for $36 \mathrm{~h}$ which is (002). The growing time does effect the orientation of the crystallite whereas the $\mathrm{Mn}$-doping does not. The concentration of $\mathrm{Mn}^{2+}$ significantly increases the spin-spin interaction in the $\mathrm{ZnO}$ : Mn nanopowder. It was observed that there was a competition between intrinsic ( $\mathrm{Zn}$ and $\mathrm{O}$ vacancies) and extrinsic $\left(\mathrm{Mn}^{2+}\right.$ ion) structural defects but still the former defects are dominant in $\mathrm{ZnO}: \mathrm{Mn}$. The effect of growing time and concentration of $\mathrm{Mn}^{2+}$ on the activation energy of $\mathrm{ZnO}$ and the $\mathrm{ZnO}$ : Mn nanopowder are calculated by Kissinger-Akahira-Sunose (KAS) and Flynn-Wall-Ozawa (FWO) methods.

\section{Introduction}

Zinc oxide $(\mathrm{ZnO})$ is an attractive material particularly in the area of electronics, photonics, acoustics and sensing. ZnO having a wide-bandgap $\left(E_{\mathrm{g}}=3.37 \mathrm{eV}\right)$ energy is a transparent semiconductor to visible light that is appropriate for short wavelength optoelectronic applications and has a large exciton binding energy ( $60 \mathrm{meV}$ ) which allows efficient excitonic emission at room temperature (RT). ${ }^{1} \mathrm{ZnO}$ nanostructured materials have attracted considerable interest from scientists because of their remarkable performance in a broad range of high technology applications such as surface acoustic wave filters, ${ }^{2}$ photonic crystals, ${ }^{3}$ photodetectors, ${ }^{4}$ light emitting diodes, ${ }^{5}$ photodiodes, ${ }^{6}$ gas sensors, ${ }^{7}$ optical modulator waveguides, ${ }^{8}$ room-temperature ultraviolent (UV) lasers $^{9}$ and solar cells. ${ }^{\mathbf{1 0 , 1 1}}$ There are several techniques to synthesize $\mathrm{ZnO}$ nanocrystals such as sol-gel processing, ${ }^{12}$ high-energy ${ }^{13}$ and cryogenic ball-

${ }^{a}$ Advanced Technology, Research and Application Center, Mersin University, Mersin, TR-33343, Turkey. E-mail: kasim.ocakoglu@mersin.edu.tr

${ }^{b}$ Faculty of Engineering, Department of Electrical-Electronics Engineering, Toros University, TR-33140 Mersin, Turkey

'Department of Energy Systems Engineering, Faculty of Technology, Mersin University, TR-33480 Tarsus, Mersin, Turkey

${ }^{d}$ Faculty of Arts and Sciences, Department of Chemistry, Mehmet Akif Ersoy University, TR-15030 Burdur, Turkey

${ }^{e}$ Institut für Physikalische Chemie, Albert-Ludwigs-Universität Freiburg, Albertstr. 21, 79104 Freiburg, Germany. E-mail: emre.erdem@physchem.uni-freiburg.de

$\uparrow$ Electronic supplementary information (ESI) available. See DOI: 10.1039/c6ra04071c milling, ${ }^{\mathbf{1 4}}$ microwave-assisted synthesis, ${ }^{\mathbf{1 5}}$ wet chemical, ${ }^{\mathbf{1 6}}$ hydrolysis/condensation, ${ }^{17}$ aerosol spray analysis ${ }^{18}$ and hydrothermal synthesis. ${ }^{19}$ Among these techniques, hydrothermal synthesis of growing $\mathrm{ZnO}$ nanocrystals has gained immense popularity because it is a cheap and easy method and does not need necessarily complex devices. ${ }^{20}$ Intrinsic defects in $\mathrm{ZnO}$ material can be listed as follows: zinc vacancy $\mathrm{V}_{\mathrm{Zn}}$, oxygen vacancy $\mathrm{V}_{\mathrm{O}}$, interstitial zinc $\mathrm{Zn}_{\mathrm{i}}$ interstitial oxygen $\mathrm{O}_{\mathrm{i}}$, and antisite oxygen $\mathrm{O}_{\mathrm{Zn}}$. Because of the recombination of free excitons $\mathrm{ZnO}$ exhibits one typical emission peak in the UV-region and one or more defect-related emission peaks in the visiblelight region. ${ }^{21}$ The origin of defect-related emission is still not very well understood and it is controversially discussed in literature. ${ }^{21-23}$ There are common hypothesis to explain the different defect emissions (violet, blue, green, yellow and orange-red) but the chemical natures of the defects responsible for these emissions are still missing. For example, it is attributed that the yellow emission caused by oxygen interstitial defects. The presence of $\mathrm{Zn}(\mathrm{OH})_{2}$ at the surface possibly occurs weak UV and the strong visible (broad yellow and green) emission peak. In addition, the orange-red emission $(640-650 \mathrm{~nm})$ is commonly attributed to the presence of excess oxygen in the samples (oxygen interstitial defects) ${ }^{24}$ or surface dislocations ${ }^{25}$ or zinc interstitial. ${ }^{26}$ Recently, Motaung et al. nicely showed that zinc and oxygen related defects play a crucial role in mediating ferromagnetism in the undoped $\mathrm{ZnO} .{ }^{18}$ On the other hand doping $\mathrm{ZnO}$ with transition metal elements like Fe, Co, Mn or Cr leads to materials with entirely different behavior towards magnetic and optical excitation. This new research direction is 
named as diluted magnetic semiconductors (DMS). ${ }^{27,28}$ DMS materials which are based on $\mathrm{ZnO}$ could show not only ferromagnetism at RT upon doping with transition metal ions, e.g. $\left(\mathrm{Fe}^{3+}\right),{ }^{29}\left(\mathrm{Cr}^{3+}\right),{ }^{30}\left(\mathrm{Co}^{2+}\right),{ }^{31}$ and $\left(\mathrm{Mn}^{2+}\right)^{16,18,32}$ but also simultaneously exhibit ferromagnetic and semiconducting properties. ${ }^{28}$ Recently, Mn doped $\mathrm{ZnO}$ revealed ferromagnetism above $\mathrm{RT}^{33}$ which is important for the new spintronic devices (spin LED's, spin valve transistors) and magneto-optic components. Contrarily, there are also works ${ }^{34}$ reporting that there is no indication of ferromagnetism nor antiferromagnetism in $\mathrm{Mn}$ doped ZnO. Interestingly, Toloman et al. reported that $\mathrm{Mn}$ doped ZnO synthesized via wet chemical route revealed ferromagnetism in the low temperature annealed samples and disappears in the samples thermally treated at high temperatures. ${ }^{16}$ Due to lack of advanced electron paramagnetic resonance (EPR) studies and insufficient characterization of the materials there is ongoing controversy ${ }^{\mathbf{2 8 , 3 3 , 3 4}}$ regarding the magnetic properties of ZnO based DMS. We believe that this study may contribute to the magnetic studies as complementary information. Here, magnetic properties of $\mathrm{ZnO}$ were excluded and we focused on more to the synthesis and characterization of the electronic and thermal properties. More specifically, we are scoping not only to understand structural changes in $\mathrm{ZnO}$ via Mn doping but also investigate the changes of local environment of doped ion $\mathrm{Mn}^{2+}$. Moreover, it is expected to get kinetic information about the structures by the aid of detailed thermal analysis.

\section{Experimental section}

\subsection{Synthesis of the $\mathrm{ZnO}$ and $\mathrm{ZnO}:$ Mn nanopowders}

The zinc nitrate hexahydrate $\left(\mathrm{Zn}\left(\mathrm{NO}_{3}\right)_{2} \cdot 6 \mathrm{H}_{2} \mathrm{O}\right.$, Acros Organics), polyethylene glycol (PEG300, Aldrich Chemistry) and ammonia $\left(\mathrm{NH}_{3}\right.$, Analar Normapur) were used as precursors to produce ZnO nanopowders by the aid of hydrothermal technique. The experiments were performed in a Teflon-lined DAH-904 autoclave (DAH-904). $2.97 \mathrm{~g}$ of $\mathrm{Zn}\left(\mathrm{NO}_{3}\right)_{2} \cdot 6 \mathrm{H}_{2} \mathrm{O}$ was dissolved in 100 $\mathrm{mL}$ of distilled water, and then $3.36 \mathrm{~g}$ PEG300 was added into the solution. The $\mathrm{pH}$ of the solution, which is important for the nanopowder formation, was adjusted to 10 by addition of $\left(\mathrm{NH}_{3}\right){ }^{35,36}$ The resulting solution was kept in Teflon-lined autoclave at $70{ }^{\circ} \mathrm{C}$ for various duration times such as $1 \mathrm{~h}, 6 \mathrm{~h}$, $12 \mathrm{~h}, 24 \mathrm{~h}$ and $36 \mathrm{~h}$. After cooling down to RT, the precipitate was filtered, washed with distilled water several times, and dried in an oven at $80{ }^{\circ} \mathrm{C}$ for $1 \mathrm{~h}$. The $\mathrm{ZnO}$ nanopowders are probably occurred by the following formation subsequent mechanisms:

$$
\begin{gathered}
\mathrm{Zn}^{2+}{ }_{(\mathrm{aq})}+n \mathrm{PEG} \leftrightarrow\left[\mathrm{Zn}(\mathrm{PEG})_{n}\right]^{2+} \\
{\left[\mathrm{Zn}(\mathrm{PEG})_{n}\right]^{2+}+4 \mathrm{OH}^{-}{ }_{(\mathrm{aq})} \leftrightarrow\left[\mathrm{Zn}(\mathrm{OH})_{4}\right]^{2-}+n \mathrm{PEG}} \\
{\left[\mathrm{Zn}(\mathrm{OH})_{4}\right]^{2-} \leftrightarrow \mathrm{ZnO} \downarrow+2 \mathrm{H}_{2} \mathrm{O}}
\end{gathered}
$$

where $n$ is an integer. The $\mathrm{Zn}$ source was primarily in the form of $\left[\mathrm{Zn}(\mathrm{PEG})_{n}\right]^{2+}$; and the remaining $\mathrm{Zn}$ source existed in the form of $\left[\mathrm{Zn}(\mathrm{OH})_{4}\right]^{2-} \cdot{ }^{37}$ Finally, further $\mathrm{ZnO}$ is obtained by decomposition of $\left[\mathrm{Zn}(\mathrm{OH})_{4}\right]^{2-}$.

The Mn-doped $\mathrm{ZnO}$ nanopowder was also synthesized with the same technique. The $\mathrm{Mn}\left(\mathrm{NO}_{3}\right)_{2} \cdot 4 \mathrm{H}_{2} \mathrm{O}$ solution was added into the solution of which is used to prepare $\mathrm{ZnO}$ nanopowder $(6 \mathrm{~h})$. A certain concentration of $\mathrm{Mn}\left(\mathrm{NO}_{3}\right)_{2} \cdot 4 \mathrm{H}_{2} \mathrm{O}$ solution was calculated according to these conditions. The Mn doped solution was kept in Teflon-lined autoclave at $70{ }^{\circ} \mathrm{C}$ for $6 \mathrm{~h}$, and then the precipitation was filtered, washed with distilled water, and were dried in an oven at $80{ }^{\circ} \mathrm{C}$ for $1 \mathrm{~h}$. Same procedure was repeated for various $\mathrm{Mn}^{2+}$ concentrations (X1: undoped, X2: $5 \times$ $10^{-4} \mathrm{~mol}$; X3: $10 \times 10^{-4} \mathrm{~mol}$; X4: $25 \times 10^{-4} \mathrm{~mol}$; X5: $75 \times 10^{-4}$ mol; X6: $100 \times 10^{-4} \mathrm{~mol}$; X7: $250 \times 10^{-4} \mathrm{~mol}$ ) of ZnO. It is obvious that the similar formation mechanisms will be followed to obtain $\mathrm{ZnO}$ : Mn nanopowders. It was observed that once the concentration of $\mathrm{Mn}^{2+}$ is increased, the color of the powders changes from light-grey to dark-grey.

\subsection{Characterization of the $\mathrm{ZnO}$ and $\mathrm{ZnO}: \mathrm{Mn}$ nanopowders}

X-ray powder diffraction patterns were collected with a Bruker D8 Advanced Series powder diffractometer at ambient temperature $\left(40 \mathrm{kV}, 40 \mathrm{~mA}, \mathrm{CuK}_{\alpha} \lambda=1.5405 \AA\right)$ in steps of $0.03^{\circ}$ for $30^{\circ}$ $\leq 2 \theta \leq 80^{\circ}$. Fourier transform infrared (FTIR) spectroscopy measurements of nanopowders were acquired using Perkin Elmer spectrometer with ATR unit. The differential thermal analysis (DTA) and thermogravimetric (TG) curves were recorded by using Seiko SII TG/DTA 7200 equipped with DTA and TG units. The thermal analyses were carried out in the temperature range of $30-1155{ }^{\circ} \mathrm{C}$ using $\alpha-\mathrm{Al}_{2} \mathrm{O}_{3}$ as a reference material while samples were in Pt crucibles. Measurements were performed under the dynamic nitrogen atmosphere with a flow rate of 50 $\mathrm{mL} \min ^{-1}$ and with different heating rates such as $5{ }^{\circ} \mathrm{C} \mathrm{min}^{-1}$, $10{ }^{\circ} \mathrm{C} \min ^{-1}$ and $15{ }^{\circ} \mathrm{C} \min ^{-1}$. Field emission-scanning electron microscopy (FE-SEM) images were recorded using a Zeiss/Supra 55 FE-SEM, and the samples were coated with Pt before the FESEM measurements. TEM images of Mn doped $\mathrm{ZnO}$ nanopowder were recorded using a JEOL-JEM-1011 transmission electron microscope (Jeol LTD., Tokyo, Japan), and pictured by Megaview III digital camera (Olympus Soft Imaging Solutions GmbH, Munster, Germany). Before the TEM pictures were recorded, the nanopowder was dispersed in ethanol and placed on a 300 mesh formvar-coated copper grid and finally dried in open air. The TEM microscope was operated at an accelerating voltage of $100 \mathrm{kV}$. The elemental analyses of the Mn doped $\mathrm{ZnO}$ nanopowders were carried out by Energy Dispersive X-ray (EDX) spectroscopy technique. The spectra were collected using Zeiss, SUPRA-55 FE-SEM equipped with an Energy Dispersive X-ray Spectrometer. Furthermore, considering the typical detection limit for EDX, the Mn concentration was also determined by using inductively coupled plasma mass spectrometry (ICP-MS) (Agilent 7500ce (Tokyo, Japan)). For ICP-MS measurements, the $\mathrm{Mn}$ : ZnO nanopowders were dissolved using the mixture of acid solution ( $3 \mathrm{~mL}$ of $\mathrm{HCl} 37 \%+1 \mathrm{~mL}$ of $\mathrm{HNO}_{3} 65 \%$ ). The EDX diffractograms and the elemental percentage of $\mathrm{Mn}$, and the results of the ICP-MS are given as ESI (Table S1 $\dagger$ ). X-band (9.47 GHz) and 
Q-band (34.2 $\mathrm{GHz}$ ) continuous-wave EPR measurements were done with Bruker EMX and ESP380 spectrometers, respectively, using rectangular TE102 (X-band) and dielectric-ring TE011 (Qband) resonators (both from Bruker) at RT. The off-set in magnetic-field were determined with polycrystalline DPPH (2diphenyl-1-picrylhydrazyl) of known $g$-factor $(g=2.0036)$.

\section{Results and discussion}

\subsection{Structural analysis of the $\mathrm{ZnO}$ and $\mathrm{ZnO}: \mathrm{Mn}$ nanopowders}

The XRD patterns of the $\mathrm{ZnO}$ nanopowders produced for various growing time and $\mathrm{Mn}^{2+}$ doping levels are shown in Fig. 1(a), enlarged in Fig. 1(b) and (c) and enlarged in Fig. 1(d), respectively.

It is obvious that the sharp diffraction patterns indicates the well crystalline structure for $\mathrm{ZnO}$ and $\mathrm{ZnO}$ : Mn samples. All the patterns of $\mathrm{ZnO}$ were indexed to hexagonal wurtzite structure with the space group of $P 6_{3} m c$ (186) (JCPDS no.: 36-1451). The lattice parameters $(a, c)$ of the $\mathrm{ZnO}$ nanopowder were calculated using the XRD data along with Bragg law $(2 d \sin \theta=n \lambda)(n=1 ; \lambda$ is the wavelength of incident X-ray used) and following formula, which is defined for hexagonal phase:

$$
\frac{1}{d^{2}}=\frac{4}{3}\left[\frac{h^{2}+h k+k^{2}}{a^{2}}\right]+\frac{l^{2}}{c^{2}}
$$

where $d$ is the distance between two different planes and $(h k l)$ are the Miller indexes. The calculated values were listed in Table 1.

The crystallinity of the powder increases with increasing growing time, as it is clear to see that the diffraction peaks become sharper. The (101) direction is the most preferred direction for all the samples except for the sample prepared for $36 \mathrm{~h}$. The $36 \mathrm{~h}$ sample was grown with the preferred direction of (002) and showed the highest intensity in this series. The crystallite size of the samples was determined from X-ray diffraction data where we prefer to use the standard (100) reflection at around $2 \theta=31.90^{\circ}$ because of its highest intensity. We apply the Scherrer's formula ${ }^{38}$ in order to quantify the average crystallite size of nanopowders.

The calculated crystallite sizes are $30 \mathrm{~nm}, 33 \mathrm{~nm}, 36 \mathrm{~nm}, 39$ $\mathrm{nm}$ and $51 \mathrm{~nm}$ for $1 \mathrm{~h}, 6 \mathrm{~h}, 12 \mathrm{~h}, 24 \mathrm{~h}$ and $36 \mathrm{~h}$, respectively. Thus, the crystallite size of $\mathrm{ZnO}$ increases upon growing time increases.

The crystal structure of $\mathrm{Mn}^{2+}$ doped $\mathrm{ZnO}$ was also characterized via XRD pattern and are shown in Fig. 1(c) and its expanded view of (100), (002) and (101) peaks in Fig. 1(d). The diffraction peaks of $\mathrm{Mn}^{2+}$ doped $\mathrm{ZnO}$ were also indexed to hexagonal structure without any impurity peaks (JCPDS no.: 030888). It is revealed that the wurtzite structure is not affected by $\mathrm{Mn}^{2+}$ doping. The unit cell parameters were calculated and given in Table 2 . Slight differences were observed in the lattice constants compared to those of undoped $\mathrm{ZnO} ; a=3.2358 \AA$ А $c=$ $5.2840 \AA$.

The XRD peak slightly shifted toward a lower angle with increased Mn concentration. This shows the increase of the lattice parameters. The ionic radius of $\mathrm{Mn}^{2+}(97 \mathrm{pm})$ is larger than that of $\mathrm{Zn}^{2+}(88 \mathrm{pm})$ in six-fold coordination. Thus, it is expected that the cell parameters are increased via $\mathrm{Mn}^{2+}$ doping. The undoped sample X1 has cell parameter $a=3.2358$ $\AA$ which increases up to $3.2685 \AA$ for the sample X7 which has the highest doping concentration. On the other hand, the effect the Mn concentration on the crystallite size is not clear as the effect of the growing time. This is because the change in the $\beta$ (full width at half maximum of XRD profile) does not proportional with the $\mathrm{Mn}^{2+}$ concentration. The calculated crystallite sizes are $32 \mathrm{~nm}, 33 \mathrm{~nm}, 21 \mathrm{~nm}, 33 \mathrm{~nm}, 31 \mathrm{~nm}$ and 35 $\mathrm{nm}$ for X2, X3, X4, X5, X6, and X7, respectively. Here we do not observe any systematic increase of size by increasing the $\mathrm{Mn}$ doping. This may due to the in homogeneous distribution of Mn ions. On one side, below certain amount of Mn concentrations, some part of the nanocrystals statistically are not doped, on the other side the remaining part contain only one Mn ion, which seems to deviate the particle size randomly. Moreover adding Mn ions changes the morphology which has great impact on the size.

\subsection{FT-IR analysis of the $\mathrm{ZnO}$ and $\mathrm{ZnO}:$ Mn nanopowders}

FT-IR was used for the detailed structural analysis of ZnO nanopowders. The FT-IR spectra of undoped ZnO nanopowder synthesized at different time intervals and doped with various $\mathrm{Mn}^{2+}$ concentrations are shown in Fig. 2(a and b), enlarged in Fig. 2(c) and (d). The observed vibration bands between 2300 $\mathrm{cm}^{-1}$ and $2400 \mathrm{~cm}^{-1}$ are assigned to the $\mathrm{CO}_{2}$ mode in air. ${ }^{39}$ The symmetric and asymmetric $-\mathrm{CH}_{2}$ stretching modes locate between $2800 \mathrm{~cm}^{-1}$ and $3000 \mathrm{~cm}^{-1}$. ${ }^{40}$ While the characteristic bands of $3500-3800 \mathrm{~cm}^{-1}$ were corresponded to stretching vibration of $\mathrm{H}_{2} \mathrm{O}$, the observed bands at $1072 \mathrm{~cm}^{-1}$ and 1030 $\mathrm{cm}^{-1}$ were attributed to the bending vibrations of -OH groups. ${ }^{41}$ The peak at $1131 \mathrm{~cm}^{-1}$ is ascribed to $\mathrm{O}-\mathrm{H}$ stretching vibration of $\mathrm{H}_{2} \mathrm{O}$ in $\mathrm{Mn}-\mathrm{Zn}-\mathrm{O}$ lattice. ${ }^{39}$ The symmetric stretching occurs between $818 \mathrm{~cm}^{-1}$ and $956 \mathrm{~cm}^{-1}$ and corresponds to the vibration of $\left(\mathrm{NO}_{3}\right)^{-1}$ ions. ${ }^{40}$ The characteristic FT-IR peaks in the region below $1000 \mathrm{~cm}^{-1}$ is very important to understand the presence of $\mathrm{Zn}-\mathrm{O}$ bond and the functional groups. Since, the vibrational modes of the metal-oxygen are expected in this region. The vibration bands observed in the range of 470-560 $\mathrm{cm}^{-1}$ were ascribed to the vibration of $\mathrm{Zn}-\mathrm{O} .{ }^{41}$ Also, the vibration bands observed in the range of $470-680 \mathrm{~cm}^{-1}$ are attributed to the stretching modes of $\mathrm{Zn}-\mathrm{Mn}-\mathrm{O} .{ }^{39}$ Besides, the sharp band observed below $1000 \mathrm{~cm}^{-1}$ in the spectrum of the Mn doped $\mathrm{ZnO}$ nanostructures is due to the $\mathrm{Mn}^{2+}$ ions implantation into the ZnO structure. These results highly suggest the incorporation of $\mathrm{Mn}^{2+}$ into $\mathrm{ZnO}$ lattice. Also, there is no absorption peak at $609 \mathrm{~cm}^{-1}$ which is characteristic for manganese oxides. ${ }^{42}$ The FT-IR peaks and their assignments of $\mathrm{ZnO}$ and $\mathrm{ZnO}: \mathrm{Mn}$ nanopowder are presented in Table 3.

\subsection{Thermal analysis of the $\mathrm{ZnO}: \mathrm{Mn}$ nanopowders}

The thermal properties of Mn-doped ZnO nanopowder (X2, X3, $\mathrm{X} 4, \mathrm{X} 5, \mathrm{X} 6$ and X7) were studied by thermogravimetric analysis from an ambient temperature up to $700{ }^{\circ} \mathrm{C}$ under nitrogen 

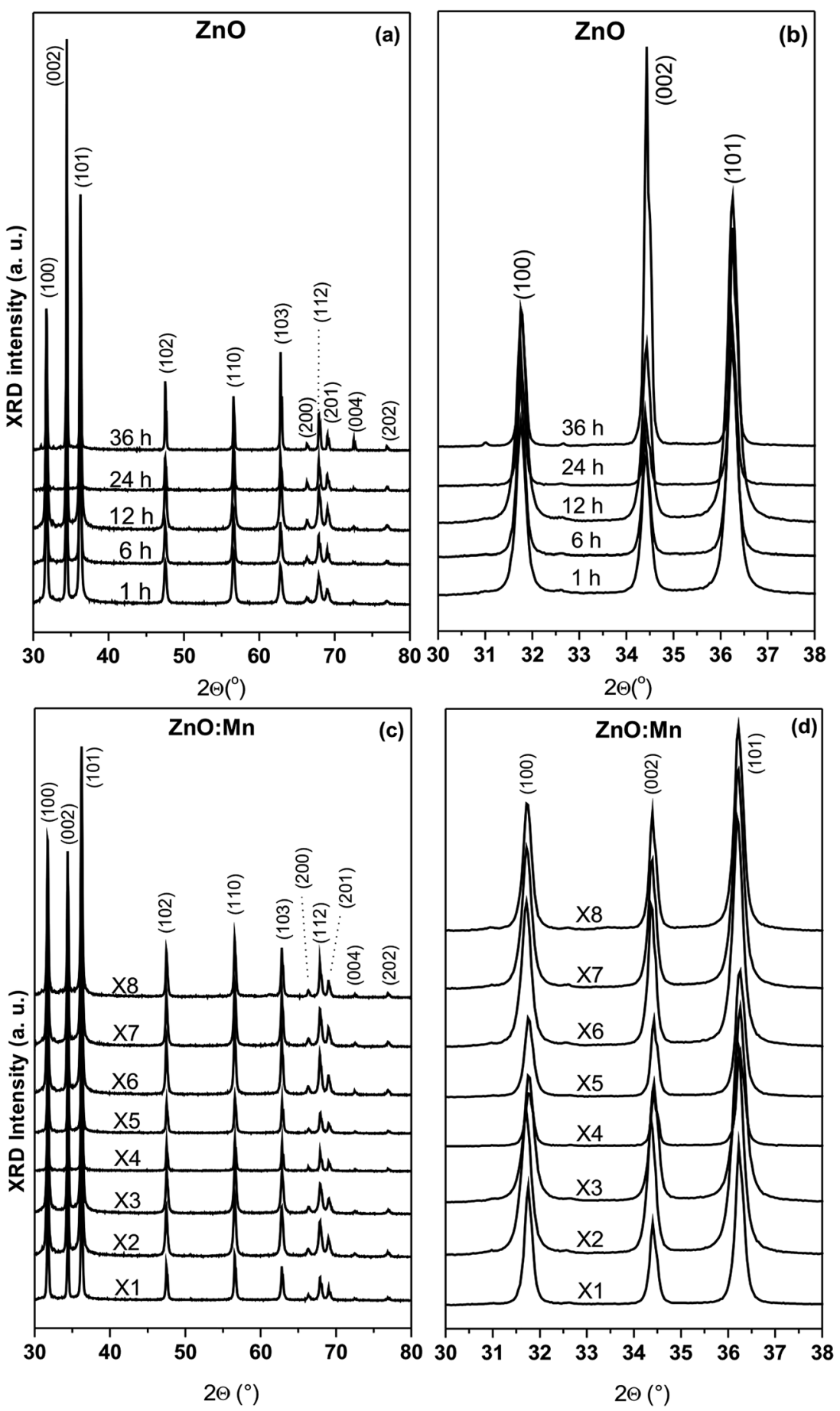

Fig. 1 (a) X-ray patterns of ZnO nanopowder depending on growing time; (b) expanded view of (100), (002) and (101) peaks in all of the samples; (c) X-ray patterns for Mn doped ZnO nanopowders depending on Mn concentration; (d) expanded view of (100), (002) and (101) peaks in all of the samples.

atmosphere. The TG/DTA curves of all samples are shown in Fig. 3(a) and (b).

The thermal decompositions of all compounds occur step by step. The TG/DTA curves of X2 are shown in Fig. 3(a) and (b). The weight losses of $\mathrm{X} 2$ occur in two steps. The first steps are in the range of room temperature to $140{ }^{\circ} \mathrm{C}$ with weight loss of $2.61 \%$ for $\mathrm{X} 2$ demonstrating the dehydration of surface- adsorbed water and decomposition of hydroxide groups. The second step occurs in the temperature range of $140-700{ }^{\circ} \mathrm{C}$ with weight loss of $1.72 \%$ for $\mathrm{X} 2$ indicating the decomposition of PEG and other impurities. The DTA curves have an obvious endothermic peak between $99{ }^{\circ} \mathrm{C}$ and $153{ }^{\circ} \mathrm{C}$ for X2 with a maximum around $164{ }^{\circ} \mathrm{C}$, which demonstrate that the decomposition of $\mathrm{OH}^{-}$groups and the removal of adsorbed 
Table 1 The lattice parameters of the $\mathrm{ZnO}$ nanopowder prepared with different growing time

\begin{tabular}{lll}
\hline & \multicolumn{2}{l}{ Lattice parameters $(\AA)$} \\
\cline { 2 - 3 } Growing time $(\mathrm{h})$ & $a$ & $c$ \\
\hline 1 & 3.2342 & 5.2815 \\
6 & 3.2358 & 5.2840 \\
12 & 3.2340 & 5.2813 \\
24 & 3.2225 & 5.2625 \\
36 & 3.2194 & 5.2573
\end{tabular}

Table 2 The lattice parameters of $\mathrm{ZnO}$ : Mn prepared with different Mn concentration

\begin{tabular}{lll}
\hline & \multicolumn{2}{l}{ Lattice parameters $(\AA)$} \\
\cline { 2 - 3 } Mn & $a$ & $c$ \\
\hline X1 (undoped) & 3.2358 & 5.2840 \\
X2 & 3.2360 & 5.2845 \\
X3 & 3.2370 & 5.2860 \\
X4 & 3.2440 & 5.2974 \\
X5 & 3.2475 & 5.3030 \\
X6 & 3.2650 & 5.3317 \\
X7 & 3.2685 & 5.3375
\end{tabular}

water take place simultaneously. These results are in agreement with the characteristics of $\mathrm{ZnO}$ nanoparticles reported in literature. ${ }^{\mathbf{4 3 4}}$ According to formation mechanism, $\mathrm{ZnO}$ is obtained by decomposition of $\left[\mathrm{Zn}(\mathrm{OH})_{4}\right]^{2-}$. It is expected that the $\mathrm{OH}^{-}$ions and $\mathrm{H}_{2} \mathrm{O}$ molecules have been adsorbed on the surface of formed $\mathrm{ZnO}$ nanopowders. We estimated that the amount of adsorbed $\mathrm{OH}^{-}$ions and $\mathrm{H}_{2} \mathrm{O}$ molecules for $\mathrm{X} 2$ sample is greater than others (X3-X7). The Mn doped $\mathrm{ZnO}$ samples (X3, X4, X5, X6 and X7) show similar decomposition characteristics: the first decompositions are shown with weight loss of $1.75 \%$ for $\mathrm{X} 3,1.16 \%$ for $\mathrm{X} 4,2.4 \%$ for $\mathrm{X} 5,2.36 \%$ for $\mathrm{X} 6$ and $2.36 \%$ for $\mathrm{X} 7$, respectively from room temperature to the range of $477-486{ }^{\circ} \mathrm{C}$ are mainly due to the removal of physically and chemically adsorbed water, the decomposition of the hydroxide group on the surface of the nanopowder. ${ }^{\mathbf{4 5 , 4 6}}$ The second decompositions are observed with weight loss of $0.4 \%$ for $\mathrm{X} 3,0.42 \%$ for $\mathrm{X} 4,0.43 \%$ for $\mathrm{X} 5,0.4 \%$ for $\mathrm{X} 6$ and $0.39 \%$ for $\mathrm{X} 7$ from 330 to $700{ }^{\circ} \mathrm{C}$. The observed weight losses are due to the decomposition of PEG and other impurities. The DTA curves of $\mathrm{X} 3-\mathrm{X} 7$ show wide endothermic peaks between $30{ }^{\circ} \mathrm{C}$ and $250{ }^{\circ} \mathrm{C}$ which demonstrate that the decomposition of $\mathrm{OH}^{-}$groups and the removal of adsorbed water. The others are attributed to the decompositions of PEG and impurities. The TG results indicate the presence of PEG on the sample surface. These results are consistent with given earlier FT-IR results.

\subsection{Kinetic analysis of the $\mathrm{ZnO}: \mathrm{Mn}$ nanopowder}

The activation energies of all compounds were calculated except of the last stages. Kinetic investigation of the last decomposition stages cannot be realized due to the fast reaction and
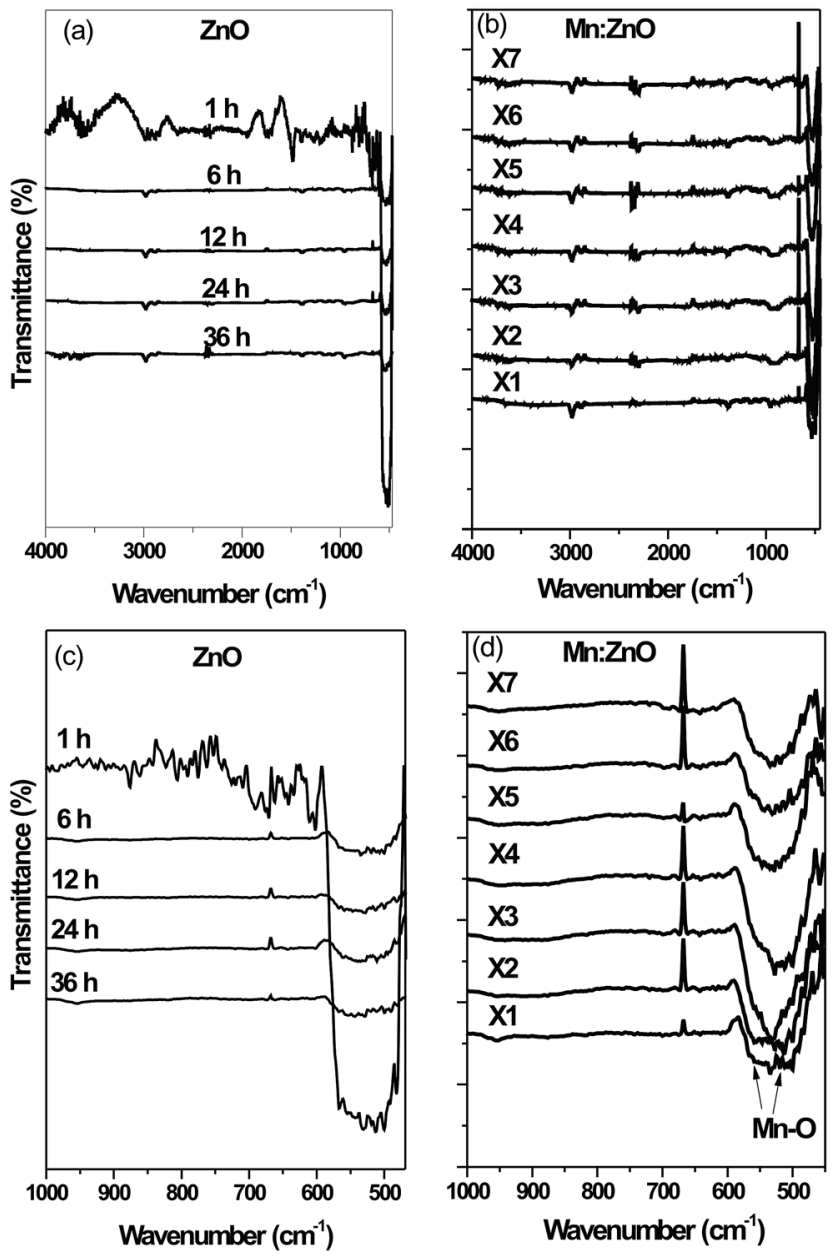

Fig. 2 (a) FT-IR spectra of $\mathrm{ZnO}$ nanopowder depending on growing time, (b) FT-IR spectra of Mn doped $\mathrm{ZnO}$ nanopowder depending on $\mathrm{Mn}$ concentration, (c) enlarged view of $\mathrm{ZnO}$ nanopowder depending on growing time, (d) enlarged view of $\mathrm{Mn}$ doped $\mathrm{ZnO}$ nanopowder.

irregular temperature data. ${ }^{47}$ The Kissinger-Akahira-Sunose (KAS) and Flynn-Wall-Ozawa (FWO) methods which are well known as model free isoconversional methods were used to calculate the activation energies of the compounds. The main assumption of these methods is that the reaction mechanism does not change with reaction conversion $(\alpha)$, temperature and heating rate. The final equations of these methods are given in following: ${ }^{48-50}$

FWO equation:

$$
\ln \beta=\left[\frac{A E_{\mathrm{a}}}{R g(\alpha)}\right]-5.3305-1.05178 \frac{E_{\mathrm{a}}}{R} \frac{1}{T}
$$

and KAS equation:

$$
\ln \frac{\beta}{T^{2}}=\left[\ln \frac{A R}{g(\alpha) E_{\mathrm{a}}}\right]-\frac{E_{\mathrm{a}}}{R} \frac{1}{T}
$$

where, $\alpha$ is the degree of conversion, $A$ is the pre-exponential factor, $\beta$ is heating rate, $T$ is absolute temperature, $E_{\mathrm{a}}$ is the activation energy, $g(\alpha)$ is an unknown function of the conversion, and $R$ is the gas constant. The graphs of $\ln \beta$ versus $1 / T$ (for 
Table 3 FT-IR frequencies obtained for $\mathrm{ZnO}$ and $\mathrm{Mn}$ doped $\mathrm{ZnO}$ nanopowder

\begin{tabular}{|c|c|}
\hline Wavenumber $\left(\mathrm{cm}^{-1}\right)$ & Assignment \\
\hline 3500-3800 (both) & Stretching vibration of $\mathrm{H}_{2} \mathrm{O}$ \\
\hline 2800-3000 (both) & $\begin{array}{l}\text { Symmetric and asymmetric }-\mathrm{CH}_{2} \\
\text { stretching modes }\end{array}$ \\
\hline 2300-2400 (both) & $\mathrm{CO}_{2}$ molecule \\
\hline 1131 (only Mn : ZnO) & $\mathrm{O}-\mathrm{H}$ stretching vibration of $\mathrm{H}_{2} \mathrm{O}$ \\
\hline 1072 and 1030 (both) & Bending vibrations of $-\mathrm{OH}$ groups \\
\hline 818-956 (both) & $\begin{array}{l}\text { Symmetric stretching vibration } \\
\text { of } \mathrm{NO}_{3}^{-1} \text { ions }\end{array}$ \\
\hline 470-560 (only undoped $\mathrm{ZnO}$ ) & Vibration of $\mathrm{Zn}-\mathrm{O}$ \\
\hline 470-680 (only $\mathrm{Mn}: \mathrm{ZnO})$ & Stretching modes of $\mathrm{Zn}-\mathrm{Mn}-\mathrm{O}$ \\
\hline
\end{tabular}

FWO equation), and the graphs of $\ln \beta / T^{2}$ versus $1 / T$ (for KAS equation) are plotted. Apparent activation energies, $E_{\mathrm{a}}$ of the decomposition reactions for the conversion degree, $\alpha$ varying in the range of 0.05-0.95 in a step of 0.05 can be calculated with using of slope values of these graphs. Kinetics Committee of the International Confederation for Thermal Analysis and Calorimetry (ICTAC) has recommended to determine the $E_{\text {a }}$ values in a wide range of a between 0.05 and 0.95 with increments of $0.05 .^{41}$ The $E_{\mathrm{a}}$ values obtained using the FWO methods are higher than that of obtained using KAS method. The $E_{\text {a }}$ versus $\alpha$ graphs for all compounds based on model-free KAS and FWO methods are shown in Fig. 4.

The $E_{\mathrm{a}}$ values of the X2 increase up to $\alpha=0.1$ and remain relatively constant in the conversion degree between 0.1 and 0.95. So it can be said that there is only one dominant kinetic process in these range of $\alpha$. The average $E_{\mathrm{a}}$ values are $127.70 \mathrm{~kJ}$ $\mathrm{mol}^{-1}$ and $133.97 \mathrm{~kJ} \mathrm{~mol}^{-1}$ calculated using the KAS and FWO methods. The $E_{\mathrm{a}}$ versus $\alpha$ graph of the X3 are showing that the $E_{\mathrm{a}}$ values decrease up to $\alpha=0.1$ and then start to increase up to $\alpha=0.45$ then again tends to decrease. The average $E_{\mathrm{a}}$ values are $79.91 \mathrm{~kJ} \mathrm{~mol}^{-1}$ and $84.63 \mathrm{~kJ} \mathrm{~mol}^{-1}$ calculated using the KAS and FWO methods. The $E_{\mathrm{a}}$ values of the X4 dramatically increase up from $\alpha=0.05$ to 0.95 . The calculated $E_{\mathrm{a}}$ values are $75.38 \mathrm{~kJ}$ $\mathrm{mol}^{-1}$ and $78.59 \mathrm{~kJ} \mathrm{~mol}^{-1}$ calculated using the KAS and FWO methods. The $E_{\mathrm{a}}$ values of the X5 increase up to $\alpha=0.6$ and reach maximum value $\left(278.45 \mathrm{~kJ} \mathrm{~mol}^{-1}\right)$ and decrease is
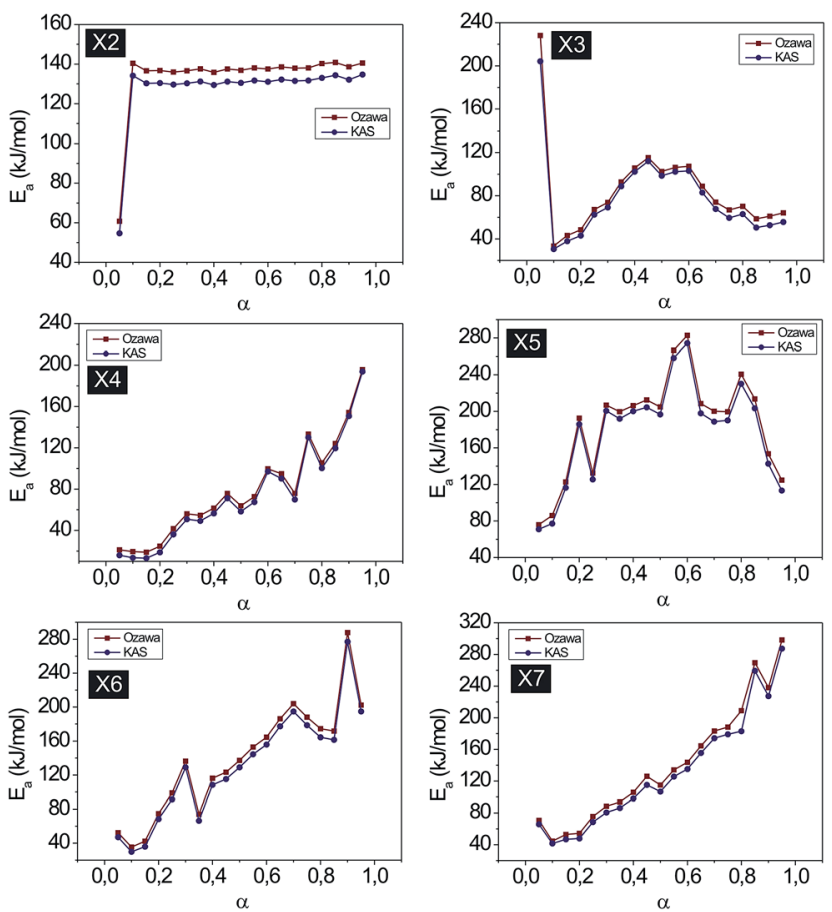

Fig. 4 The $E_{\mathrm{a}}$ versus $\alpha$ graphs for all compounds based on model-free KAS and FWO methods.

observed immediately after this decomposition ratio up to $\alpha=$ 0.95 . The average $E_{\mathrm{a}}$ values are $166.82 \mathrm{~kJ} \mathrm{~mol}^{-1}$ and $183.18 \mathrm{~kJ}$ $\mathrm{mol}^{-1}$ calculated using the KAS and FWO methods. It is seen that the $E_{\mathrm{a}}$ values of $\mathrm{X} 6$ are increasing in irregular. The activation energy values of the $\mathrm{X} 6$ increase with an increase in the conversion degree up to $\alpha=0.25$. A partial decrease is observed immediately after this decomposition ratio, but after then the activation energy increases again and reaches maximum value at $\alpha=0.90\left(282.52 \mathrm{~kJ} \mathrm{~mol}^{-1}\right)$. After reaching the maximum value, the activation energy decreases again. The average $E_{\mathrm{a}}$ values are $131.02 \mathrm{~kJ} \mathrm{~mol}^{-1}$ and $136.95 \mathrm{~kJ} \mathrm{~mol}^{-1}$ calculated using the KAS and FWO methods. It is observed that the $E_{\mathrm{a}}$ values persistently increase with an increase in the decomposition ratio for the $\mathrm{X} 7$ and then decrease. The average $E_{\mathrm{a}}$ values are calculated as $130.77 \mathrm{~kJ} \mathrm{~mol}^{-1}$ and $138.55 \mathrm{~kJ} \mathrm{~mol}^{-1}$ by the KAS and FWO methods. These results show that there are multi-step
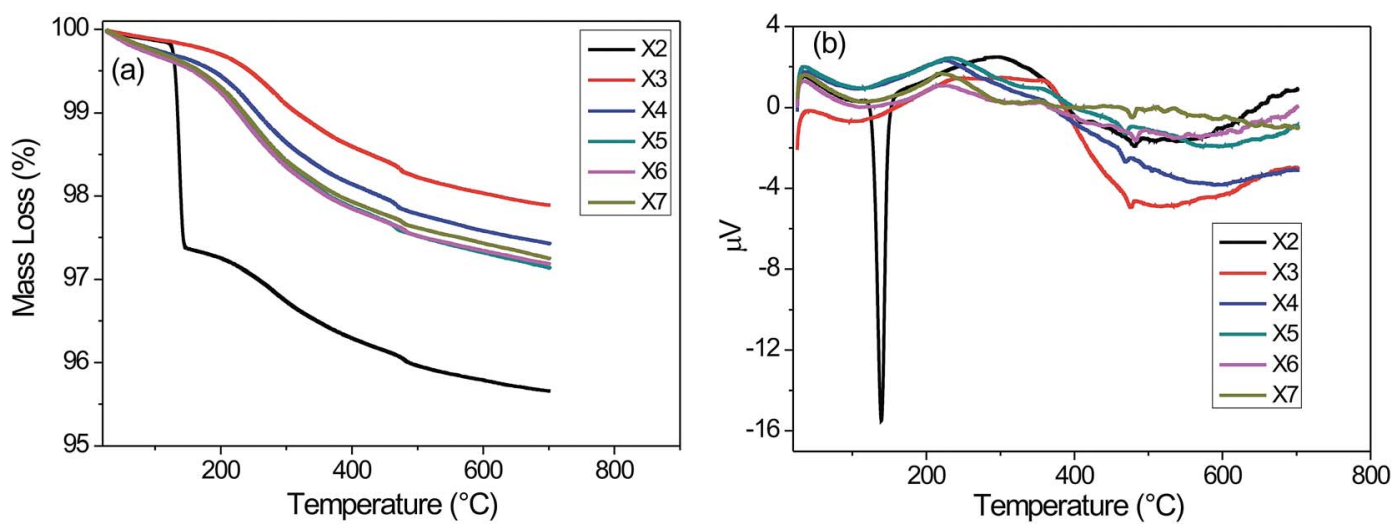

Fig. 3 Thermal gravimetric and differential thermal analysis of ZnO : Mn nanopowder: (a) TG and (b) DTA graphs. 
Table 4 The values of the activation energy $E_{a}$, of the first decomposition processes

\begin{tabular}{lcc}
\hline Compounds & $\begin{array}{l}\text { FWO method, } \\
\mathrm{kJ} \mathrm{mol}^{-1}\end{array}$ & $\begin{array}{l}\text { KAS method, } \\
\mathrm{kJ} \mathrm{mol}^{-1}\end{array}$ \\
\hline X2 & 133.97 & 127.70 \\
X3 & 84.63 & 79.91 \\
X4 & 78.59 & 75.38 \\
X5 & 183.18 & 166.82 \\
X6 & 136.95 & 131.02 \\
X7 & 138.55 & 130.77 \\
\hline
\end{tabular}

kinetic processes for $\mathrm{X} 3$ to $\mathrm{X} 7$. All results are summarized in Table 4.

\subsection{Elemantal and microstructure analysis of the $\mathrm{ZnO}$ and ZnO : Mn nanopowders}

The features of nanomaterials are strongly affected by the chemical composition. The EDX results show chemical composition of the nanoparticles and presence of manganese content (Fig. S1 $\dagger$ ). The ICP result revealed that the amount of manganese which was incorporated into the $\mathrm{ZnO}$ crystal lattice increases proportionally with the amount used in the preparation step for each samples as it was summarized in ESI (Table S1†).

Field emission-scanning electron microscopy (FE-SEM) was used to examine the morphology of the nanopowder. FE-SEM images of the $\mathrm{ZnO}$ nanopowder synthesized for different time durations by using hydrothermal method are shown in the Fig. 5.

The powder morphology revealed more or less nanorod shape. The lengths of the nanorods are in the scale of the micrometers $(1-7 \mu \mathrm{m})$ and their diameters are in the range of 100 to $200 \mathrm{~nm}$. The $\mathrm{ZnO}$ nanorods obtained at $1 \mathrm{~h}$ time duration are in the pyramid-like structure, whereas the ones obtained at $6 \mathrm{~h}, 12 \mathrm{~h}$ and $36 \mathrm{~h}$ are in the nanoneedle form. Finally those synthesized at $24 \mathrm{~h}$ are in the form of nanorods. On the other hand, macroscopic images show that generally ZnO nanorods are indeed in the flower-like structure. Fig. 6 shows typical FESEM images of the samples synthesized with different concentration of Mn ranging from $5 \times 10^{-4} \mathrm{~mol}$ to $250 \times 10^{-4} \mathrm{~mol}$. Fig. 6 reveals a large quantity of well-defined nanorods. These nanorods are of uniform size, smooth surface as shown in the SEM images of the samples. The FE-SEM image reveals that each flower-like structure consisted of closely packed pyramidlike rods. On the other hand, ZnO nanorods composed of nanoneedle-shaped as shown in the SEM images. Especially, while X1 sample resembles nanoneedles, others look like pyramid-like structures. Also, end portions of undoped $\mathrm{ZnO}$ nanorods are not in the form of pyramid-like. The diameter of the nanorods gradually becomes smaller along the growth direction. The average diameter and the length of Mn doped ZnO nanorods are $100-200 \mathrm{~nm}$ and $1-3 \mu \mathrm{m}$, respectively. The diameter is about $70 \mathrm{~nm}$ at the tip. The low-magnification FESEM image demonstrates that the typical products consist of

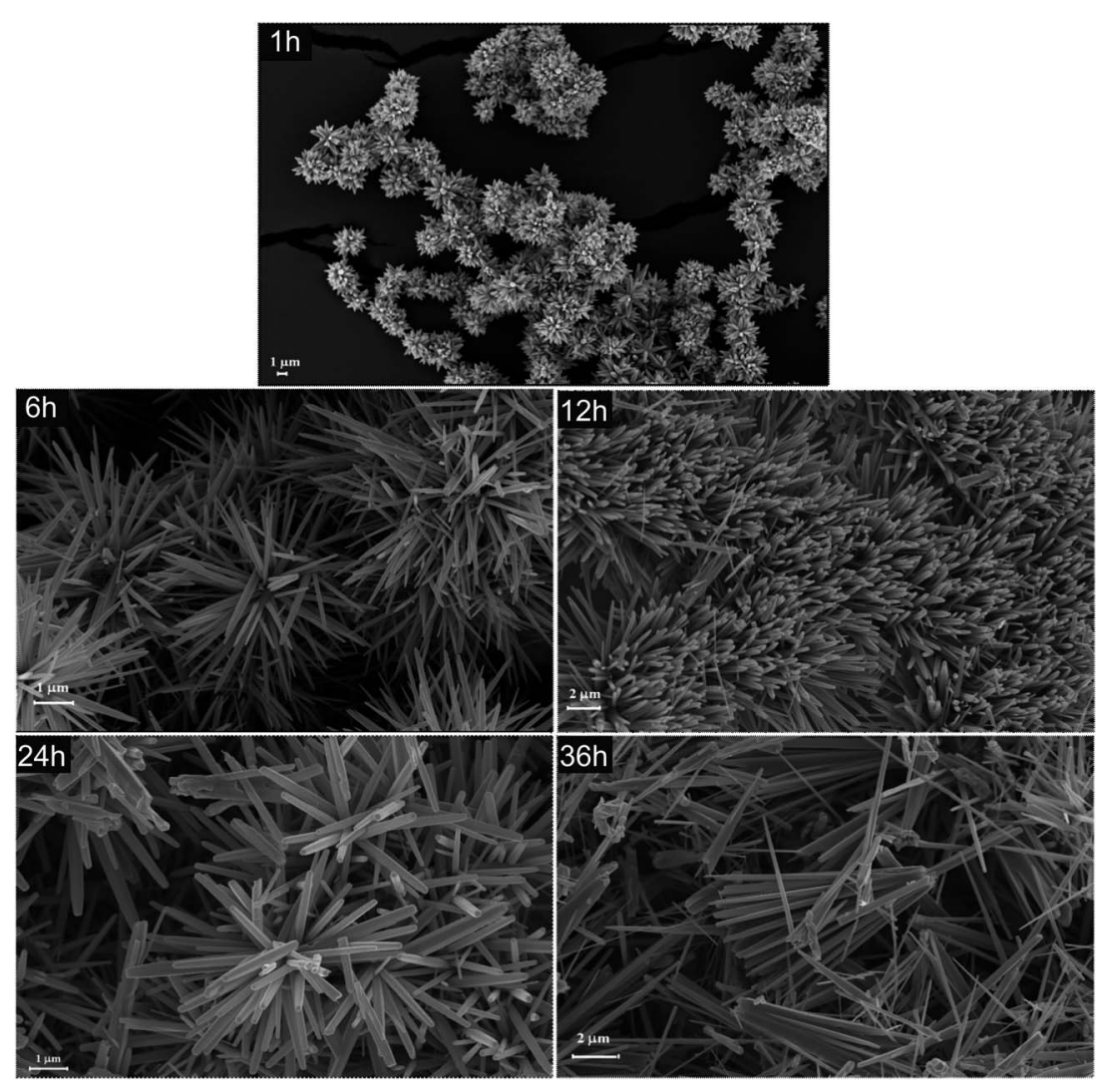

Fig. 5 FE-SEM images of undoped $\mathrm{ZnO}$ nanopowder. 

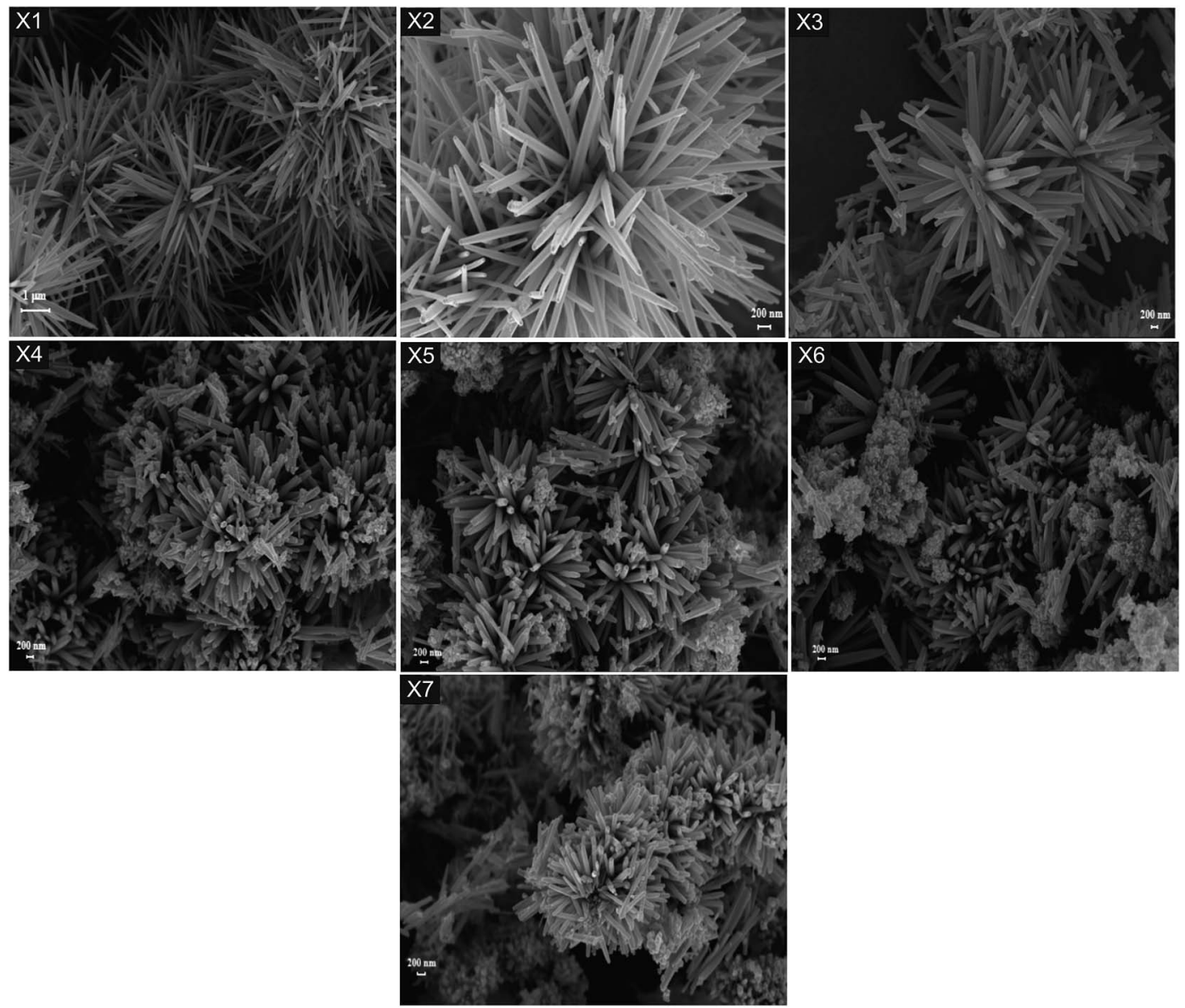

Fig. 6 FE-SEM images of $\mathrm{Mn}$ doped $\mathrm{ZnO}$ nanopowder.

a large quantity of well-dispersed rods structures. The images show an abundance of nearly flowerlike particles of undoped and Mn-doped $\mathrm{ZnO}$ nanorods. It can be seen that Mn doping in ZnO nanorods seems to have small influence on size and the morphology of the as-synthesized samples.

Fig. 7 shows the TEM images of the samples synthesized in different concentration of $\mathrm{Mn}^{2+}$ ranging from $5 \times 10^{-4} \mathrm{~mol}$ to $250 \times 10^{-4} \mathrm{~mol}$. As it is mentioned before, the FE-SEM images show that the Mn doped $\mathrm{ZnO}$ includes both nanoneedles and nanorods structure. The TEM images confirm that this nanopowder was formed mainly in nanorods shape. The diameters of the nanorods are getting smaller along the edge of the rods. It is possible to control the morphologies such as flowerlike, spindlelike, swordlike or umbellarlike structure of $\mathrm{ZnO}$ by controlling the reagents used. ${ }^{37}$

\subsection{EPR spectroscopy analysis of the $\mathrm{ZnO}$ and $\mathrm{ZnO}: \mathrm{Mn}$ nanopowders}

EPR spectroscopy was applied to investigate the influence of the growing time and the $\mathrm{Mn}$ concentration on the electronic properties of $\mathrm{ZnO}$ samples. The spin-Hamiltonian concept is applied for the theoretical description of the observed EPR spectra. Details of the theoretical background of Mn doped metal oxide has been described by us elsewhere. ${ }^{51-54}$ In Fig. 8(a)
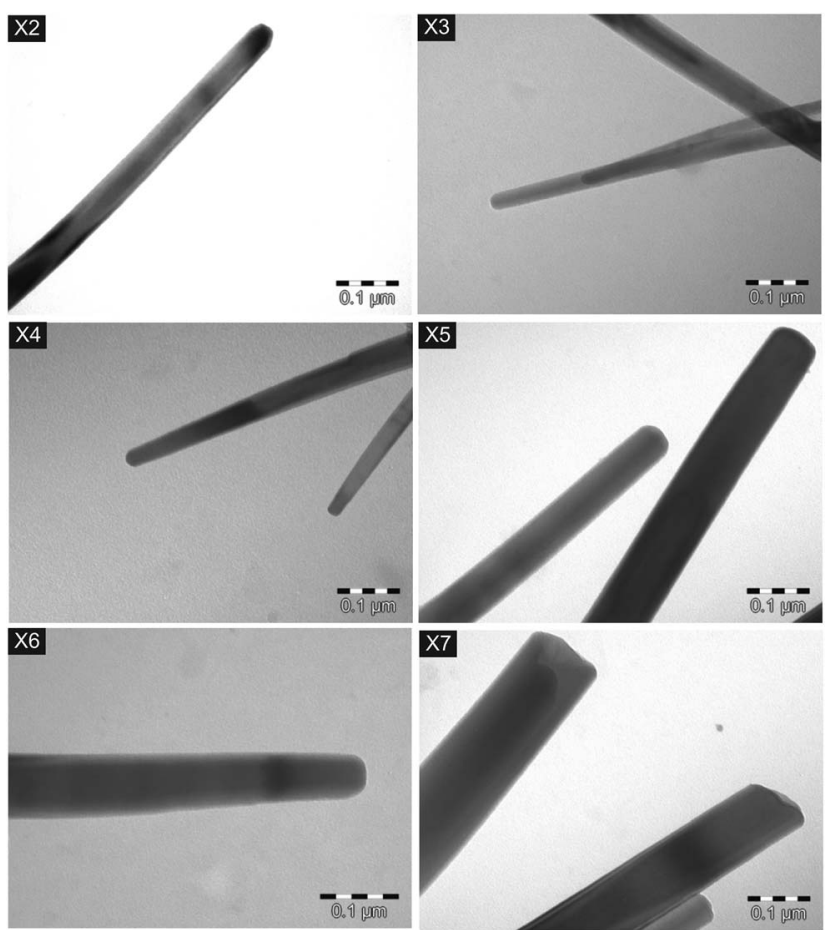

Fig. 7 TEM images of $\mathrm{Mn}$ doped $\mathrm{ZnO}$ nanopowder 

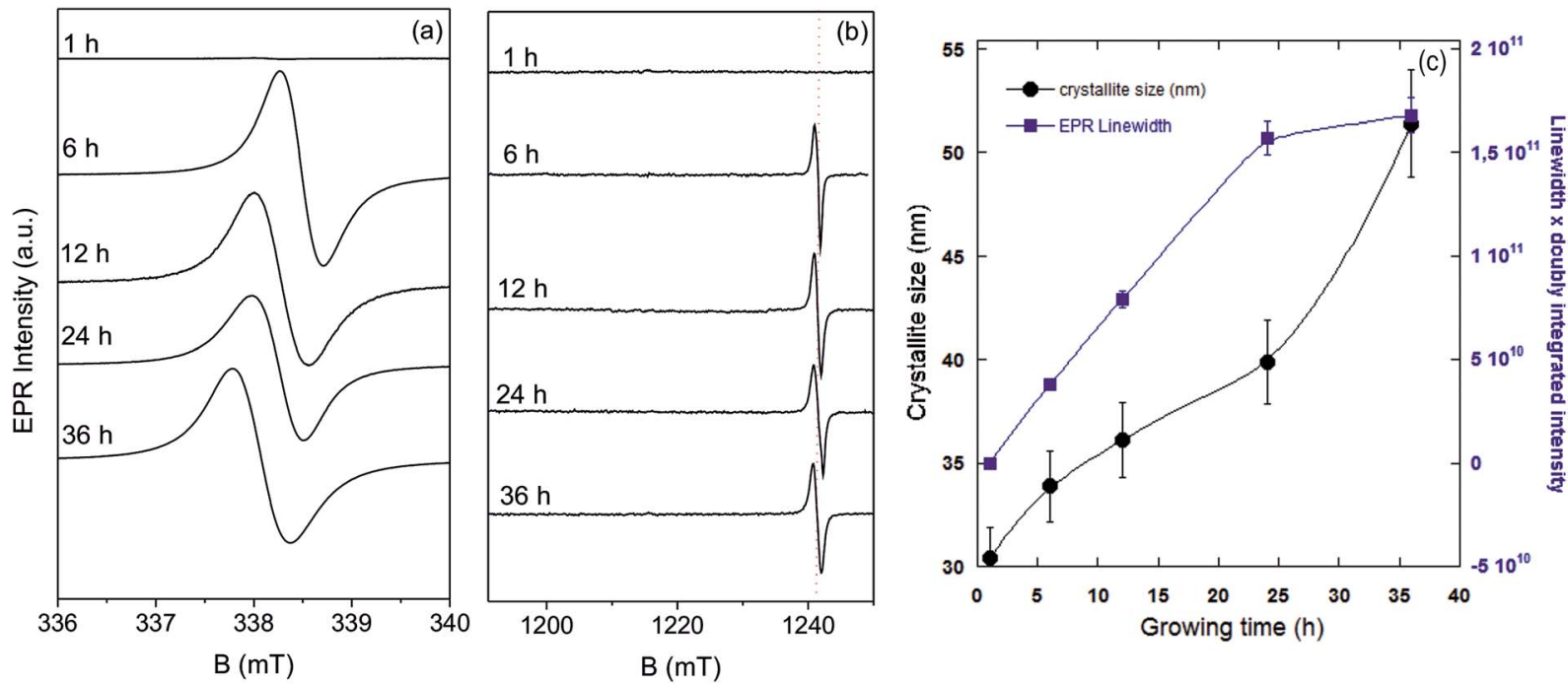

Fig. 8 The EPR spectra of undoped $\mathrm{ZnO}$ depending on growing time (a) X band; (b) $\mathrm{Q}$ band; (c) comparison of the change in crystallite size and EPR linewidth by growing time deduced from $X$-band spectra.

and (b) we present EPR results of undoped samples depending on growing time both measured by $\mathrm{X}$ and $\mathrm{Q}$ band. Except the $\mathrm{l} \mathrm{h}$ sample, all samples revealed EPR signal at $g=1.9620$ indicating symmetry breaking oxygen or zinc vacancies \{Jakes, $2011 \# 491$; Parashar, 2012 \#585\}. This shows that $1 \mathrm{~h}$ hydrothermal treatment is not enough to reach the formation energy of defects to form intrinsic defects in ZnO crystal. From the X band results the linewidth multiplied by peak area has been calculated and we observed increase of defect concentration by growing time (Fig. 8(c)). The linewidth increase given in Fig. 8(c) can be also attributed to a distortion of crystal field. That shows also the continuous broadening of the EPR lines by increasing hydrothermal treatment time is due to exchange effects. The effects of
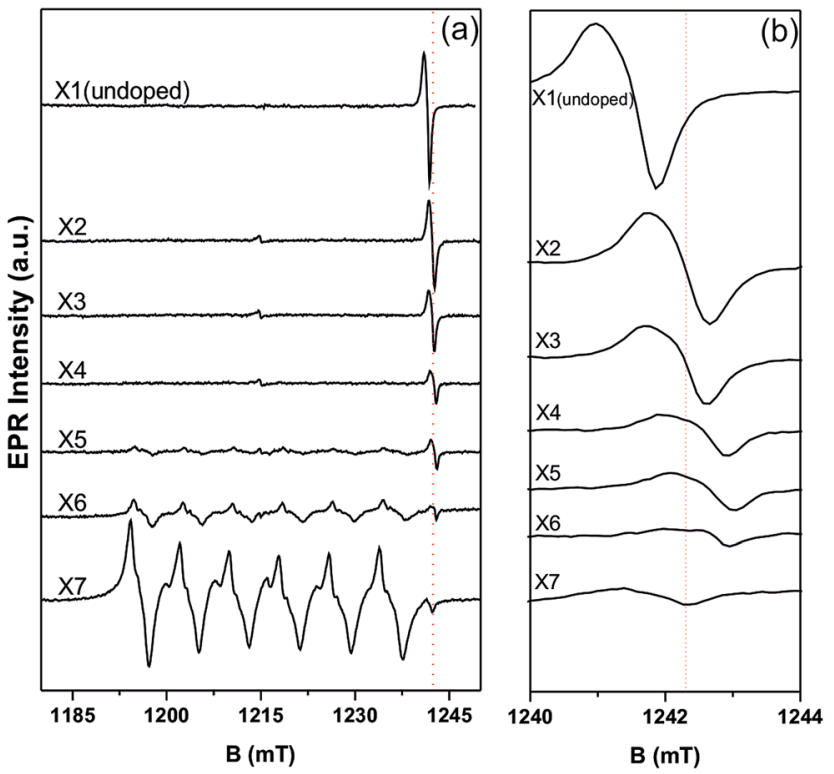

Fig. 9 (a) $\mathrm{Q}$ band EPR spectra of $\mathrm{Mn}$ doped $\mathrm{ZnO}$ samples with different Mn concentrations, (b) expanded view. the growing time on the crystallite size and EPR linewidth are compared in the Fig. 8(c). We conclude that increasing the growing time increases the crystallite size, and further the defects. It is shown in Fig. 9 that the Mn doped samples revealed typical hyperfine resolved sextet line in X5, X6 and X7 samples in $\mathrm{Q}$ band spectra. That is an indication that below some certain $\mathrm{Mn}$ concentration the $\mathrm{Mn}^{2+}$ ions still not incorporating at the $\mathrm{ZnO}$ lattice. Due to spin-spin interactions the highest Mn concentrated (X7) sample revealed line broadening compare to $\mathrm{X} 5$ and $\mathrm{X} 6$. The sample $\mathrm{X} 4$ shows the competition between intrinsic and extrinsic defects. It is seen that intrinsic defects still dominate to EPR signal even doping by $\mathrm{Mn}^{2+}$ ions. It is known that the defects in crystals particularly on the surface play an important role for catalytic activity. ${ }^{55,56}$

\section{Conclusions}

In this work undoped and doped $\mathrm{ZnO}$ nanorods have been synthesized and the structural, thermal and electronic properties were investigated with several methods. We found that crystal structure is pure and $\mathrm{Mn}$ ions incorporated in $\mathrm{ZnO}$ lattice after certain concentration values. TEM results revealed nicely resolved homogeneously distributed rod shape $\mathrm{ZnO}$ nanostructures. By the thermal analysis decomposition of $\mathrm{ZnO}$ has been investigated by using two different semi-empirical models. FT-IR results revealed all vibrational modes and these results are totally in agreement with the EPR results. Modifications in crystal structure can be attributed to either intrinsic defects such as oxygen vacancies and $\mathrm{Zn}$ vacancies or also the external doping ions $\mathrm{Mn}^{2+}$. The oxidation state of $\mathrm{Mn}$ ion also determined as $2+$ via EPR spectroscopy. Competing effects between intrinsic and extrinsic defects has been investigated and this will contribute to not only to understand the local coordination of $\mathrm{Mn}^{2+}$ ions in $\mathrm{ZnO}$ lattice but also to determine the solubility limit of $\mathrm{Mn}^{2+}$ ions. ${ }^{57}$ The change in the crystallite size and EPR linewidth 
deduced from X-band spectra upon growing time are compared and correlated. It is observed that both are increased by growing time which is a clear indication of symmetry reduction by increase level of Mn concentration. Also this shows strong spinspin exchange interaction at higher level of Mn doping. Moreover the intrinsic defects such as vacancies observed in undoped ZnO EPR spectra is quenched via Mn doping.

\section{Acknowledgements}

This research has been financially supported by the Deutsche Forschunsgemeinschaft, DFG (Grant: Er 662/1-2) and The Scientific and Technological Research Council of Turkey, TUBITAK (Grant: 110M803) in the framework of European Science Foundation (ESF-EUROCORES-EuroSolarFuels-10-FP006). Continuous support of $S$. Weber is gratefully acknowledged.

\section{References}

1 A. B. Djurisic, W. C. H. Choy, V. A. L. Roy, Y. H. Leung, C. Y. Kwong, K. W. Cheah, T. K. G. Rao, W. K. Chan, H. T. Lui and C. Surya, Adv. Funct. Mater., 2004, 14, 856-864. 2 N. W. Emanetoglu, C. Gorla, Y. Liu, S. Liang and Y. Lu, Mater. Sci. Semicond. Process., 1999, 2, 247-252.

3 Y. F. Chen, D. Bagnall and T. F. Yao, Mater. Sci. Eng., B, 2000, 75, 190-198.

4 H. Kind, H. Q. Yan, B. Messer, M. Law and P. D. Yang, Adv. Mater., 2002, 14, 158.

5 N. Saito, H. Haneda, T. Sekiguchi, N. Ohashi, I. Sakaguchi and K. Koumoto, Adv. Mater., 2002, 14, 418.

6 J. Y. Lee, Y. S. Choi, J. H. Kim, M. O. Park and S. Im, Thin Solid Films, 2002, 403, 553-557.

7 P. Mitra, A. P. Chatterjee and H. S. Maiti, Mater. Lett., 1998, 35, 33-38.

8 M. H. Koch, P. Y. Timbrell and R. N. Lamb, Semicond. Sci. Technol., 1995, 10, 1523-1527.

9 M. H. Huang, S. Mao, H. Feick, H. Q. Yan, Y. Y. Wu, H. Kind, E. Weber, R. Russo and P. D. Yang, Science, 2001, 292, 18971899.

10 M. Law, L. E. Greene, J. C. Johnson, R. Saykally and P. D. Yang, Nat. Mater., 2005, 4, 455-459.

11 A. B. F. Martinson, J. W. Elam, J. T. Hupp and M. J. Pellin, Nano Lett., 2007, 7, 2183-2187.

12 D. W. Bahnemann, C. Kormann and M. R. Hoffmann, J. Phys. Chem., 1987, 91, 3789-3798.

13 S. K. S. Parashar, B. S. Murty, S. Repp, S. Weber and E. Erdem, J. Appl. Phys., 2012, 111, 113712.

14 H. Kaftelen, K. Ocakoglu, S. Tu, R. Thomann, S. Weber and E. Erdem, Phys. Rev. B: Condens. Matter Mater. Phys., 2012, 86, 014113.

15 J. J. Schneider, R. C. Hoffmann, J. Engstler, A. Klyszcz, E. Erdem, P. Jakes, R. A. Eichel, L. Pitta-Bauermann and J. Bill, Chem. Mater., 2010, 22, 2203-2212.

16 D. Toloman, A. Mesaros, A. Popa, O. Raita, T. D. Silipas, B. S. Vasile, O. Pana and L. M. Giurgiu, J. Alloys Compd., 2013, 551, 502-507.
17 A. W. Cohn, K. R. Kittilstved and D. R. Gamelin, J. Am. Chem. Soc., 2012, 134, 7937-7943.

18 D. E. Motaung, I. Kortidis, D. Papadaki, S. S. Nkosi, G. H. Mhlongo, J. Wesley-Smith, G. F. Malgas, B. W. Mwakikunga, E. Coetsee, H. C. Swart, G. Kiriakidis and S. S. Ray, Appl. Surf. Sci., 2014, 311, 14-26.

19 W. J. Li, E. W. Shi, Y. Q. Zheng and Z. W. Yin, J. Mater. Sci. Lett., 2001, 20, 1381-1383.

20 S. Baruah and J. Dutta, J. Sol-Gel Sci. Technol., 2009, 10, 013001.

21 S. Repp and E. Erdem, Spectrochim. Acta, Part A, 2016, 152, 637-644.

22 A. B. Djurisic, Y. H. Leung, K. H. Tam, Y. F. Hsu, L. Ding, W. K. Ge, Y. C. Zhong, K. S. Wong, W. K. Chan, H. L. Tam, K. W. Cheah, W. M. Kwok and D. L. Phillips, Nanotechnology, 2007, 18, 095702.

23 E. Erdem, J. Alloys Compd., 2014, 605, 34-44.

24 X. Liu, X. H. Wu, H. Cao and R. P. H. Chang, J. Appl. Phys., 2004, 95, 3141-3147.

25 H. J. Fan, R. Scholz, F. M. Kolb, M. Zacharias, U. Gosele, F. Heyroth, C. Eisenschmidt, T. Hempel and J. Christen, Appl. Phys. A: Mater. Sci. Process., 2004, 79, 1895-1900.

26 G. Manabu, O. Naoko, O. Kenichi and K. Mikio, Jpn. J. Appl. Phys., 2003, 42, 481.

27 V. Avrutin, N. Izyumskaya, U. Ozgur, D. J. Silversmith and H. Morkoc, Proc. IEEE, 2010, 98, 1288-1301.

28 I. Djerdj, G. Garnweitner, D. Arcon, M. Pregelj, Z. Jaglicic and M. Niederberger, J. Mater. Chem., 2008, 18, 5208-5217.

29 S. Q. Zhou, K. Potzger, G. Talut, H. Reuther, K. Kuepper, J. Grenzer, Q. Y. Xu, A. Mucklich, M. Helm, J. Fassbender and E. Arenholz, J. Phys. D: Appl. Phys., 2008, 41, 105011.

30 L. B. Duan, X. R. Zhao, J. M. Liu, T. Wang and G. H. Rao, Appl. Phys. A: Mater. Sci. Process., 2010, 99, 679-683.

31 N. Akdogan, A. Nefedov, K. Westerholt, H. Zabel, H. W. Becker, C. Somsen, R. Khaibullin and L. Tagirov, J. Phys. D: Appl. Phys., 2008, 41, 165001.

32 Q. Y. Xu, H. Schmidt, L. Hartmann, H. Hochmuth, M. Lorenz, A. Setzer, P. Esquinazi, C. Meinecke and M. Grundmann, Appl. Phys. Lett., 2007, 91, 092503.

33 P. Sharma, A. Gupta, K. V. Rao, F. J. Owens, R. Sharma, R. Ahuja, J. M. O. Guillen, B. Johansson and G. A. Gehring, Nat. Mater., 2003, 2, 673-677.

34 J. Alaria, P. Turek, M. Bernard, M. Bouloudenine, A. Berbadj, N. Brihi, G. Schmerber, S. Colis and A. Dinia, Chem. Phys. Lett., 2005, 415, 337-341.

35 J. Qiu, B. Weng, L. Zhao, C. Chang, Z. Shi, X. Li, H.-K. Kim and Y.-H. Hwang, J. Nanomater., 2014, 2014, 211.

36 J. Zhang, L. Sun, J. Yin, H. Su, C. Liao and C. Yan, Chem. Mater., 2002, 14, 4172-4177.

37 X. Wang, Q. Zhang, Q. Wan, G. Dai, C. Zhou and B. Zou, J. Phys. Chem. C, 2011, 115, 2769-2775.

38 S. Erat, H. Metin and M. Arä, Mater. Chem. Phys., 2008, 111, 114-120.

39 M. Ashokkumar and S. Muthukumaran, Opt. Mater., 2014, 37, 671-678.

40 N. Rajamanickam, R. N. Mariammal, S. Rajashabala and K. Ramachandran, J. Alloys Compd., 2014, 614, 151-164. 
41 L.-H. Li, J.-C. Deng, H.-R. Deng, Z.-L. Liu and L. Xin, Carbohydr. Res., 2010, 345, 994-998.

42 M. Pashchanka, R. C. Hoffmann, O. Burghaus, B. Corzilius, G. Cherkashinin and J. J. Schneider, Solid State Sci., 2011, 13, 224-231.

43 V. I. Anisimkin, M. Penza, A. Valentini, F. Quaranta and L. Vasanelli, Sens. Actuators, B, 1995, 23, 197-201.

44 J. M. Wang and L. Gao, Inorg. Chem. Commun., 2003, 6, 877881.

45 V. I. Anisimkim, M. Penza, A. Valentini, F. Quaranta and L. Vasanelli, Sens. Actuators, B, 1995, 23, 197-201.

46 M. Li, B. Hari, X. Lv, X. Ma, F. Sun, L. Tang and Z. Wang, Mater. Lett., 2007, 61, 690-693.

47 M. Ak, G. K. Çılgı, F. D. Kuru and H. Cetișli, J. Therm. Anal. Calorim., 2012, 111, 1627-1632.

48 H. Cetişli, G. K. Çılgı and R. Donat, J. Therm. Anal. Calorim., 2012, 108, 1213-1222.

49 N. Chaiyo, R. Muanghlua, S. Niemcharoen, B. Boonchom, P. Seeharaj and N. Vittayakorn, J. Therm. Anal. Calorim., 2011, 107, 1023-1029.
50 G. K. Cilgi, H. Cetisli and R. Donat, J. Therm. Anal. Calorim., 2012, 110, 127-135.

51 E. Aksel, P. Jakes, E. Erdem, D. M. Smyth, A. Ozarowski, J. van Tol, J. L. Jones and R.-A. Eichel, J. Am. Ceram. Soc., 2011, 94, 1363-1367.

52 E. Erdem, M. Drahus, R. A. Eichel, A. Ozarowski, J. Van Tol and L. C. Brunel, Ferroelectrics, 2008, 363, 39-49.

53 H. Kaftelen, M. Tuncer, S. Tu, S. Repp, H. Gocmez, R. Thomann, S. Weber and E. Erdem, J. Mater. Chem. A, 2013, 1, 9973-9982.

54 B. Y. Price, G. Hardal, M. Acikgoz, S. Repp and E. Erdem, J. Appl. Phys., 2015, 118, 175705.

55 S. Gil Girol, T. Strunskus, M. Muhler and C. Woll, J. Phys. Chem. B, 2004, 108, 13736-13745.

56 G. R. Li, T. Hu, G. L. Pan, T. Y. Yan, X. P. Gao and H. Y. Zhu, J. Phys. Chem. C, 2008, 112, 11859-11864.

57 T. Ruf, S. Repp, J. Urban, R. Thomann and E. Erdem, J. Nanopart. Res., 2016, 18, 109. 